\title{
Cultura Cultura
}

Revista de Historia Teorid das ldeaias - Revista de História e Teoria das Ideias

Vol. 30 | 2012

A justiça na Antiguidade

\section{A justiça na Antiguidade}

\section{Leonor Santa Bárbara e Francisco Caramelo}

\section{OpenEdition}

Journals

Edição electrónica

URL: http://journals.openedition.org/cultura/1532

DOI: $10.4000 /$ cultura. 1532

ISSN: 2183-2021

\section{Editora}

Centro de História da Cultura

\section{Edição impressa}

Data de publição: 1 dezembro 2012

Paginação: 8-9

ISSN: 0870-4546

\section{Refêrencia eletrónica}

Leonor Santa Bárbara e Francisco Caramelo, «A justiça na Antiguidade », Cultura [Online], Vol. 30

2012, posto online no dia 15 maio 2014, consultado a 22 setembro 2020. URL : http://

journals.openedition.org/cultura/1532 ; DOI : https://doi.org/10.4000/cultura.1532

Este documento foi criado de forma automática no dia 22 setembro 2020.

(c) CHAM - Centro de Humanidades / Centre for the Humanities 


\title{
A justiça na Antiguidade
}

\author{
Leonor Santa Bárbara e Francisco Caramelo
}

1 A noção de justiça tem tido sempre uma função importante na história da humanidade e particularmente na Antiguidade. Nas civilizações pré-clássicas, a justiça é sinónimo de ordem e depende da vontade e da legitimidade que é conferida pelos deuses. No mundo clássico, na Odisseia, Homero alude à justiça, embora o poeta que na época arcaica mais se ocupa deste valor tenha sido Hesíodo. Autores posteriores, como Platão, Aristóteles, Epicuro ou Cícero, entre outros, abordam esta questão, ainda que nem sempre da mesma maneira.

2 Homens e cidadãos, os Gregos orgulhavam-se da sua liberdade que, em parte, se reflectia no facto de apenas obedecerem a uma lei, igual para todos. Distinguiam, contudo, entre dois tipos de lei - a divina, não-escrita, conjunto de valores universais, comuns a todos, e a humana, escrita, específica para cada cidade, mas que deveria obedecer à divina. Por outro lado, o Direito Romano foi, ao longo dos séculos e até muito recentemente, a base do Direito europeu e ocidental. No entanto, a civilização europeia possui, além do legado clássico, uma matriz judaico-cristã, o que justifica que a abordagem do tema seja feita em civilizações aparentemente tão díspares e distantes como o Egipto, a Mesopotâmia, Grécia e Roma. Convidaram-se investigadores e especialistas com o fim de se proceder a um diálogo amplo e rico, cujo resultado se apresenta neste volume.

Os textos aqui reunidos tiveram a sua origem no colóquio que, entre 16 e 17 de Junho de 2010, se realizou na FCSH/UNL, dedicado ao tema da Justiça na Antiguidade. Procurámos debater aqui questões como a importância da Justiça na vida do indivíduo e do cidadão; o modo como esta noção evoluiu ao longo da Antiguidade; a forma como foi encarada pelos diversos autores/textos; qual a sua contribuição para o bem comum da cidade e para o seu desenvolvimento; qual a sua relação com a lei.

4 A publicação destes textos na Cultura, revista do $\mathrm{CHC}$, é pertinente, não só devido à interdisciplinaridade desta unidade de investigação, mas ainda ao facto de este colóquio ter sido organizado por um dos seus grupos de investigação: Estudos da Antiguidade. Infelizmente - e por motivos que não dependem da nossa vontade - 
algumas das contribuições do colóquio não se encontram aqui. Mas surgiram outras, dentro da mesma área, que contribuem para a unidade e riqueza do projecto.

5 A terminar, uma palavra de agradecimento a todos aqueles que contribuíram para este volume, começando pelos investigadores que participaram no debate, o enriqueceram e enviaram o seu texto para publicação. Ao Professor Doutor João Luís Lisboa, Director do $\mathrm{CHC}$, que acolheu o projecto desde o início, queremos deixar também o nosso agradecimento. Finalmente, uma palavra para o Director da revista Cultura, Professor Doutor José Esteves Pereira, e para o Subdirector da mesma, o Professor Doutor Luís Manuel Bernardo, cujo trabalho possibilitou esta publicação.

\section{AUTORES}

\section{LEONOR SANTA BÁRBARA}

É Professora Auxiliar do Departamento de Estudos Portugueses da FCSH/UNL, onde lecciona Grego, Literatura Grega e Cultura Clássica Grega, entre outras matérias. Além disso, é investigadora do Centro de História da Cultura da mesma Universidade, onde é responsável pelo grupo de investigação de Estudos da Antiguidade. Licenciada em Línguas e Literaturas Clássicas pela Faculdade de Letras da Universidade de Lisboa, obteve na mesma instituição os graus de Mestre e Doutor em Literatura Grega com dissertações que abordam a literatura do período helenístico, sendo a última sobre O Pessimismo Grego no Período Helenístico.

She teaches Greek, Greek Literature and Greek Classical Culture in the Department of Portuguese Studies, at FCSH/UNL. She is also a researcher in the Centro de História da Cultura, where she is responsible for the research group of Studies in Antiquity. With a undergraduate and Master's degree in Classical Languages and Literatures from the Faculdade de Letras da Universidade de Lisboa, she gained her PhD at the same University with a dissertation on the Greek Literature in the Hellenistic age: O Pessimismo Grego no Período Helenístico.

\section{FRANCISCO CARAMELO}

Licenciado em História pela FCSH da UNL. Mestre em História das Civilizações Pré-Clássicas e Doutor em Civilizações Pré-Clássicas (área da Assiriologia) pela mesma universidade. Professor Associado com Agregação na FCSH da UNL, tem leccionado sobre História do Médio Oriente Antigo e História das Religiões na Antiguidade. As suas áreas de investigação são História das Religiões e particularmente a linguagem profética. A sua tese de mestrado, publicada, intitula-se A Mensagem Política de Jeremias na Crise de 609-587 a. C.; a sua tese de doutoramento, também publicada, intitula-se A Linguagem Profética na Mesopotâmia (Mari e Assíria). Tem-se dedicado também à arqueologia no Médio Oriente, em particular na Síria, onde desenvolveu escavações em Tall as-Sin, Tall Humeida e Tall Abu al-'Atiq. É subdirector do Projecto Arqueológico Médio Eufrates Sírio.

Degree in History (FCSH - Nova University); Master in History of Pre-Classic Civilizations (FCSH Nova University); Ph.D. in Pre-Classic Civilizations - Assyriology (FCSH - Nova University). Associate Professor with Aggregation (FCSH - Nova University). Teaching fields: History of the Ancient Middle East and History of Religions in Antiquity. Research fi elds: History of Religions 
and particularly Prophetic Language. Master thesis which was published: Political Message of Jeremiah during the Crisis of 609-587 BC; Ph.D. thesis which was published: Prophetic Language in Mesopotamia (Mari and Assyria). Archaeological work in Syria. Excavations developed in Tall as-Sin, Tall Humeida and Tall Abu-al-'Atiq. Subdirector of the Arc haeological Project Syrian Middle Euphrates. 